\title{
Interactions between the cannabinoid and the serotonergic systems in modulation of pain perception
}

\author{
Hristina Nocheva ${ }^{1}, Z_{\text {Zafer Sabit }}{ }^{1}$, Dimitar Bakalov$^{1}$, Evgeni Grigorov ${ }^{2}$ \\ 1 Department of Pathophysiology, Faculty of Medicine, Medical University of Sofia, Sofia, Bulgaria \\ 2 Faculty of Pharmacy, Medical University of Varna, Varna, Bulgaria \\ Corresponding author: Hristina Nocheva (hndimitrova@medfac.mu-sofia.bg)
}

Received 9 December 2019 • Accepted 2 January 2020 • Published 8 January 2021

Citation: Nocheva H, Sabit Z, Bakalov D, Grigorov E (2021) Interactions between the cannabinoid and the serotonergic systems in modulation of pain perception. Pharmacia 68(1): 109-115. https://doi.org/10.3897/pharmacia.68.e49219

\begin{abstract}
The aim of our study was to evaluate the effects of cannabinoids and serotonergic system on nociception in intact rats and after heat stress. Cannabinoid receptor type 1 (CB1) and 5-hydroxytryptamine receptor $\left(5 \mathrm{HT}_{1 \mathrm{~A}}\right)$ agonists and antagonists have been administered according to different experimental designs (alone and in combinations) in intact male Wistar rats, as well in animals subjected to one hour of heat stress. Pain perception has been evaluated by Paw pressure test. Our results pointed out that cannabinoids and the serotonergic system interact in nociception in intact animals as well as after heat stress. Cannabinoids seemed to have less prominent role in such interaction in intact animals than after heat stress. The interplay between the two systems probably involves different mechanisms in intact animals and after heat stress with time-dependent effects. The interaction between the cannabinoid and the serotonergic systems exerts a modulating rather than mediating effect on h-SIA.
\end{abstract}

\section{Keywords}

cannabinoids, nociception, Paw pressure test, stress induced analgesia, serotonergic system

\section{Introduction}

In the last three decades the endogenous cannabinoid system (ECS) has received increasing research attention due to its implication in many physiological (emotion, memory, sleep, metabolic function, etc.) and pathological (pain and inflammation) processes (Mechoulam and Parker 2013). The cannabinoid receptor type 1 (CB1) has a ubiquitous distribution predominantly in the central nervous system. It belongs to the superfamily of seven-transmembrane-spanning G-protein-coupled receptors and is the most abundant G-protein-coupled receptor in the brain. Its activation seems to modulate calcium or potassium conductance with a resulting effect on neuronal excitability and neurotransmitter release (Ohno-Shosaku et al. 2001; Howlett 2005) with direct interaction with the monoaminergic system (Schlicker et al. 1997; Lau and Schloss 2008; Esteban and García-Sevilla 2012). It turns out that many of the cannabinoid effects are mediated by changes in serotonin (5-HT) or dopamine levels (Darmani et al. 2003; Lau and Schloss 2008; Seyrek et al. 2010).

The serotonergic system has been traditionally associated with mood disorders (Casaril et al. 2019), motor control (Kawashima 2018), and even potentially life threatening conditions (Koleva and Nikolov 2018). Implication of the serotonergic system in pain control has also been demonstrated. 5-HT receptors have been classified 
into 14 subtypes, and some subclasses (the $5-\mathrm{HT}_{1 \mathrm{~A}}$ among them) are expressed within the spinal cord. Activation of $5-\mathrm{HT}_{1 \mathrm{~A}}$ receptors causes opening of $\mathrm{K}^{+}$and closing of $\mathrm{Ca}^{2+}$ channels through negatively coupling to adenylate cyclase (Boess and Martin1994). Both pro- and anti-nociceptive effects have been described after $5-\mathrm{HT}_{1 \mathrm{~A}}$ receptors' activation (Basbaum and Fields 1984; Millan 2002; Yoshimura and Furue 2006).

In vivo effects of interaction between the cannabinoids and the serotonergic system have been evaluated mainly in connection with their impact on memory, affective and cognitive disorders (Egashira et al. 2002; Bambico et al. 2012), or represent in vitro studies (Nakazi et al. 2000).

Our study was focused on in vivo effects of cannabinoids and serotonergic system interaction on pain perception. Experiments involved intact animals as well as animals subjected to heat stress, since possible differences in the effects of the mediators in physiologic and pathologic conditions were also expected.

Physical and psychological stress exposure triggers a broad spectrum of physiological responses designated to increase chances for escape, survival, and homeostasis restoration. Synchronization between the nervous, the endocrine and the immune systems characterizes the stress-reaction of the body with apposite behavioral, autonomic and cognitive responses. Along with the undeniable importance of the stress reaction for stress coping, it is also true that such a reaction could unleash pathologic conditions and diseases of nervous, cardiovascular, gastrointestinal, reproductive systems (van Dijk and Buwalda 2008; Lupien et al. 2009; Maletic and Raison 2009; Goldstein 2011).

Several physiologic parameters, pain perception among them, change during acute stress exposure - a phenomenon known as stress-induced analgesia (SIA). Since SIA develops along with stress itself and is underlined by the same mechanisms engaged in the stress-response, it could be regarded as an indirect marker for the stress-reaction. On the other hand, SIA depends also on pathways that suppress pain perception. Understanding the mechanisms underlying SIA could give interesting clues for both stress- and pain-control.

\section{Materials and methods of research}

\section{Animals}

The experiments were carried out on male Wistar rats (180-200g). Animals were housed individually in polypropylene boxes with free access to food and water. Constant temperature environment $\left(22 \pm 2^{\circ} \mathrm{C}\right)$ on a $12 \mathrm{~h} \mathrm{light} /$ dark cycle (lights on at 6.00 a.m.) was provided. All experiments were carried out between 10:00 a.m. and 1:00 p.m.

All procedures were approved by the Animal Care and Use Committee of the Medical University of Sofia and BFSA.

\section{Acute model of heat stress (1h HS)}

Animals were placed in thermal chamber at $38{ }^{\circ} \mathrm{C}$ for 1 hour. During the time of stress free movements were allowed, but no food or water was provided.

\section{Substances}

CB1-agonist $\mathrm{N}$-arachidonoyl-ethanolamine (or anandamide, AEA, $1 \mathrm{mg} / \mathrm{kg}$ ) and $\mathrm{CB} 1$-antagonist $\mathrm{N}$-(Piperidin-1-yl)-5-(4-iodophenyl)-1-(2,4-dichlorophenyl)-4-methyl-1H-pyrazole-3-carbox-amide (AM251, $1,25 \mathrm{mg} / \mathrm{kg}$ ) were purchased from Sigma Aldrigh; $5 \mathrm{HT}_{1 \mathrm{~A}}{ }^{-}$ agonist (R)-(+)-8-Hydroxy-DPAT hydrobromide (DPAT, $1 \mathrm{mg} / \mathrm{kg}$ ) and $5 \mathrm{HT}_{1 \mathrm{~A}}$ - antagonist NAN-190 hydrobromide (NAN, 1mg/kg) were purchased from Tocris Bioscience (Bristol, UK). All substances were administered intraperitoneally (i.p.) dissolved in DMSO.

\section{Nociception assessment}

Ugo Basile analgesimeter was used in order to estimate changes in the mechanical nociceptive (PP-) thresholds of experimental animals -Paw pressure (PP, Randall-Selitto) test. Pressure was applied to the hind-paw and the value (in arbitrary units, $A U$ ) required to elicit a nociceptive response (such as squeak or struggle) was taken as the mechanical nociceptive threshold. A cut-off value of $500 \mathrm{~g}$ was observed to prevent damage of the paw.

\section{Statistical analysis}

The results were statistically assessed by one-way analysis of variance (ANOVA) followed by t-test comparison, and represented as mean \pm S.E.M. Values of $\mathrm{p}<0.05$ were considered to indicate statistical significance.

\section{Results and discussion}

Administration of CB1-agonist $\mathrm{AEA}$ and $5 \mathrm{HT}_{1 \mathrm{~A}}$-agonist DPAT in intact animals (int+AEA+DPAT, Fig. 1A) decreased PP-thresholds compared to controls during the first $30 \mathrm{~min}$ of the experiment; an increase in PP-thresholds was observed after that period. When AEA and DPAT were administered after CB1-antagonist AM251 (int+AM251+AEA+DPAT, Fig. 1A) PP-thresholds remained comparable to controls till the $40^{\text {th }}$ min of the experiment with an increase following that period. Administration of $5 \mathrm{HT}_{1 \mathrm{~A}}$-antagonist NAN190 (int+NAN+AEA+DPAT, Fig. 1A) instead increased PP-thresholds for the entire time of the experiments compared to controls and int+AM251+AEA+DPAT. int+NAN+AEA+DPAT-animals showed higher PPthresholds compared to int+AEA+DPAT for the first $30 \mathrm{~min}$ of the experiment (Fig. 1A).

Serotonin and endogenous cannabinoids have been both demonstrated to take part in pain perception modulation. The spinal $5 \mathrm{HT}_{1 \mathrm{~A}}$-receptor has most commonly been 

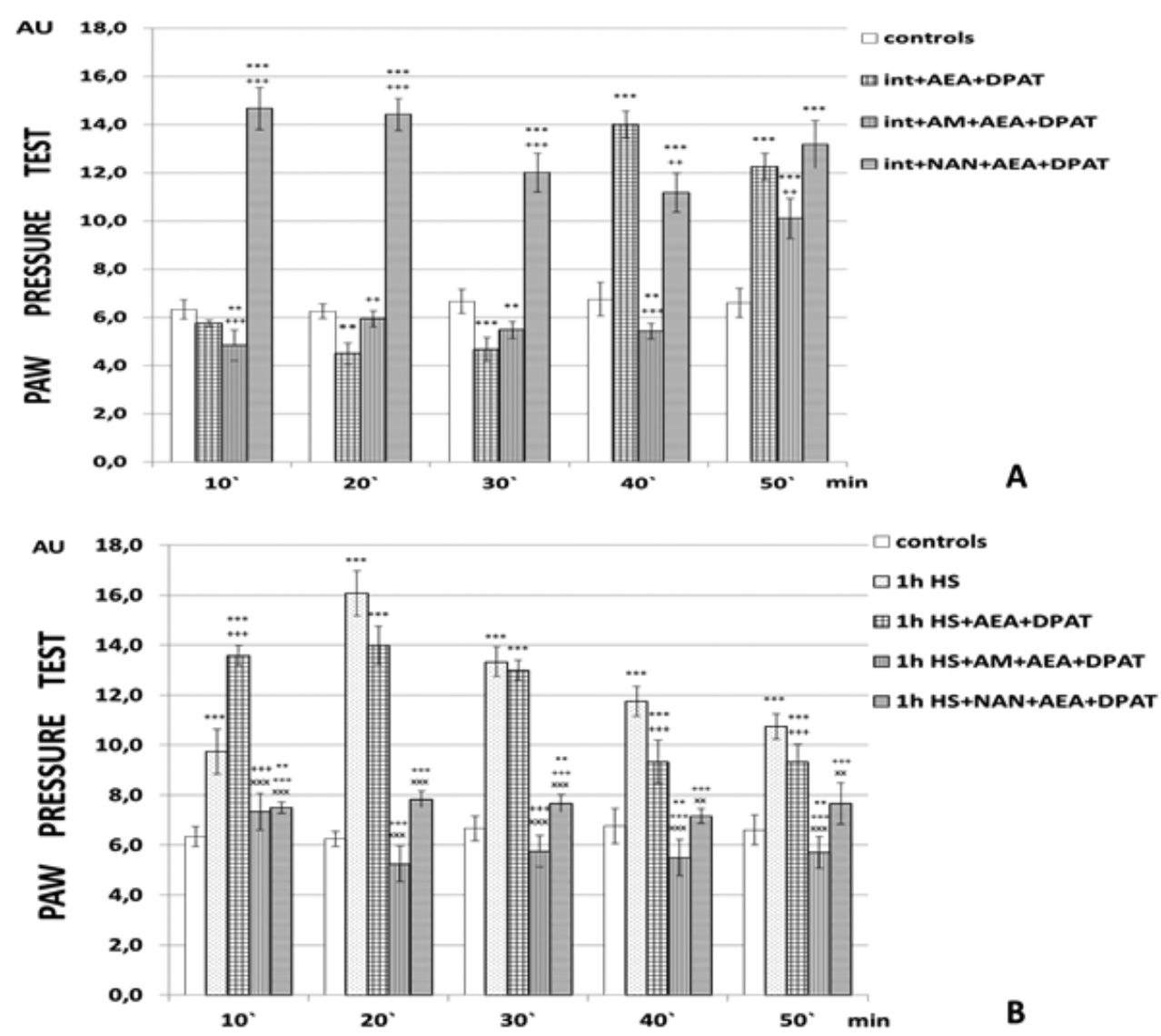

Figure 1. Effects of $\mathrm{CB} 1$ - and $5 \mathrm{HT}_{1 \mathrm{~A}}$-agonists (AEA+DPAT) administration on nociceptive (PP) thresholds in (A) intact animals (int) and (B) animals subjected to 1 hour of heat stress (1 h HS) without and after pretreatment with CB1- and $5 \mathrm{HT}_{1 \mathrm{~A}}$-antagonists (AM and NAN, respectively). PP-thresholds are represented as mean values \pm S.E.M. in arbitrary units (AU).

${ }^{* * *} \mathrm{p}<0.001,{ }^{* *} \mathrm{p}<0.01$ vs. controls. A. ${ }^{+++} \mathrm{p}<0.001,{ }^{++} \mathrm{p}<0.01$ vs. int $+\mathrm{AEA}+\mathrm{DPAT}$. B. ${ }^{+++} \mathrm{p}<0.001$ vs. 1 h HS; ${ }^{\mathrm{xxx}} \mathrm{p}<0.001$, ${ }^{\mathrm{xx}} \mathrm{p}<0.01$ vs. 1 h HS+AEA+DPAT.

reported to promote antinociception (Colpaert 2006; Mico et al. 2006; Salzer and Boehm 2018), yet activation of medullary $5 \mathrm{HT}_{1 \mathrm{~A}}$-autoreceptors had an opposite effect (Wei and Pertovaara 2006). The cannabinoid system is usually associated with analgesic effects (Woodhams et al. 2017).

The interplay between the serotonergic system and the ECS may involve changes in the release of eCB and/or 5 -HT, common second messengers, as well as other mediatory systems. Data exist that endocannabinoids (eCBs) may influence the firing rate of 5-HT neurons (Patel et al. 2005), or induce changes in 5-HT-levels (Haj-Dahmane and Roh-Yu S 2011). If eCBs had a direct effect on 5-HT-levels, the PP-threshold curves for animals with $\mathrm{AEA}+\mathrm{D}$ PAT should show some similarities with NAN+DPAT (if AEA decreased 5-HT-levels) or with animals with DPAT alone (if AEA increased 5-HT-levels).

In our experiments the PP-curve of int+AEA+DPAT indeed resembled the one for int+DPAT (Fig. 2A), while AEA alone caused a transient analgesia during the first 20 min. A dependence of pain modulation by the brain $5 \mathrm{HT}_{1 \mathrm{~A}}$-receptor availability in healthy human subjects has been demonstrated (Martikainen et al. 2007). It is possible that in intact (i.e. non stressed) subjects the serotonergic system plays a more prominent role for pain perception than the cannabinoid system. Yet, each one of the two an- tagonists (for the $\mathrm{CB} 1$ - and the $5 \mathrm{HT}_{1 \mathrm{~A}}$-receptor) changed the shape of the PP-thresholds curve, suggesting that both the systems accomplish for the final outcome. Constitutive activity could explain such findings - CB1 are agonist-independently active with an impact on the serotonergic system.

1 hour of heat stress (Fig. 1B) increased PP-thresholds compared to controls during the whole time of the experiment.

Administration of AEA and DPAT after the end of 1h HS (1h HS+AEA+DPAT, Fig. 1B) decreased heat stress-induced analgesia (h-SIA) from the $20^{\text {th }} \mathrm{min}$ on (on the $30^{\text {th }}$ min $1 \mathrm{~h}$ HS and $1 \mathrm{~h}$ HS+AEA+DPAT showed no statistically relevant differences between them). PP-thresholds were still higher than control levels for the entire time of the experiment (Fig. 1B).

Both $\mathrm{CB1}$ - and $5 \mathrm{HT}_{1 \mathrm{~A}}$-receptor antagonist's administration before the agonists (1h HS+AM+AEA+DPAT; 1h HS+NAN+AEA+DPAT, Fig. 1B) decreased h-SIA. lh HS+AM+AEA+DPAT-animals showed a more prominent decrease in PP-thresholds compared to $1 \mathrm{~h}$ $\mathrm{HS}+\mathrm{NAN}+\mathrm{AEA}+\mathrm{DPAT}$-animals (Fig. 1B).

In an additional experimental trial, DPAT and AEA were administered each one alone in intact animals and after $1 \mathrm{~h}$ HS. DPAT administration in intact animals 


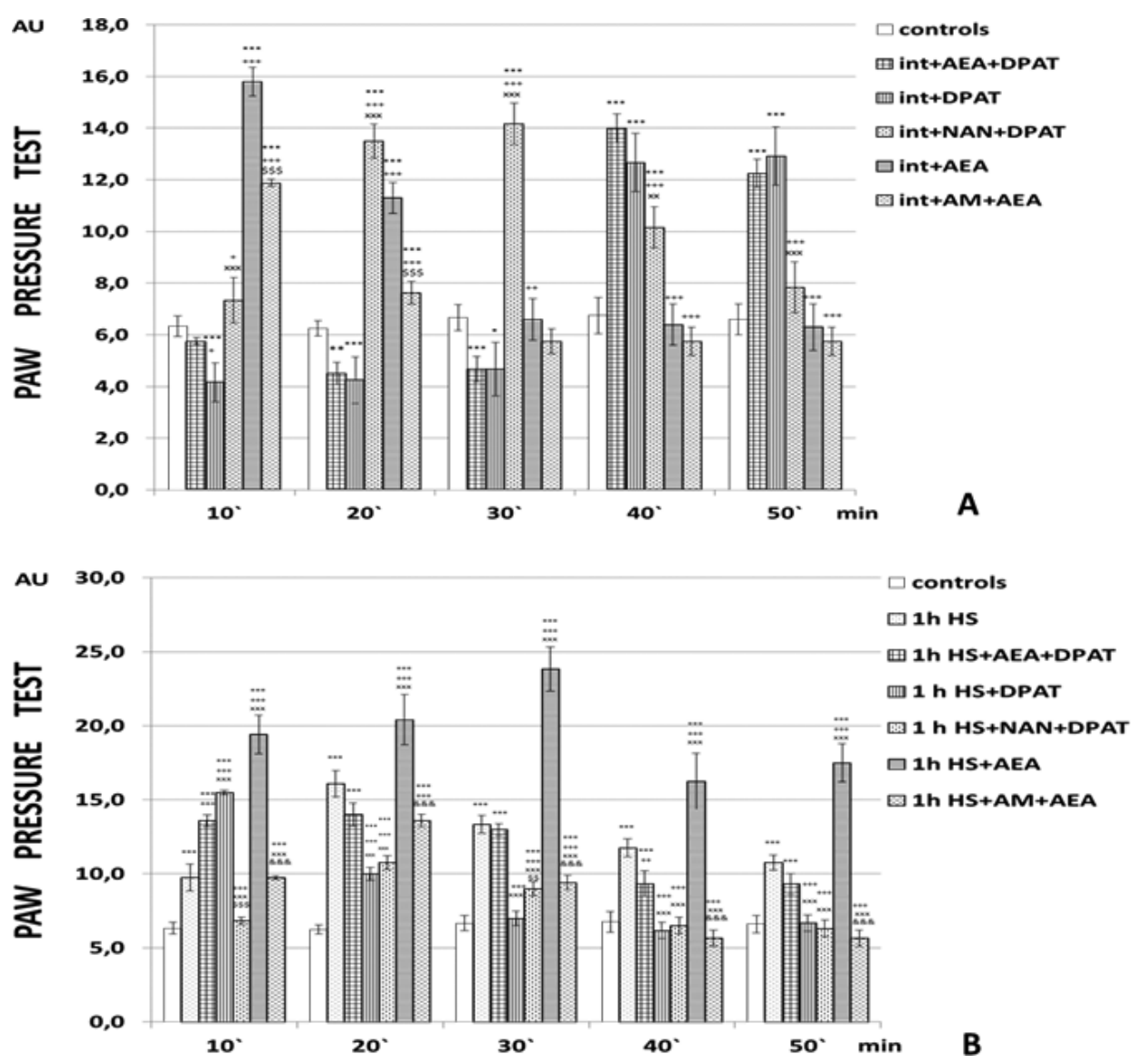

Figure 2. Effects of CB1-agonist (AEA) and 5HT1A-agonists (DPAT) alone administration on nociceptive (PP) thresholds in (A) intact animals (int) and (B) animals subjected to 1 hour of heat stress (1h HS) without and after pretreatment with CB1- and 5HT1A-antagonists (AM and NAN, respectively). PP-thresholds are represented as mean values \pm S.E.M. in arbitrary units (AU). ${ }^{* * *} \mathrm{p}<0.001,{ }^{* *} \mathrm{p}<0.01,{ }^{*} \mathrm{p}<0.05$ vs. controls. A. ${ }^{++} \mathrm{p}<0.001,{ }^{++} \mathrm{p}<0.01$ vs. int+AEA+DPAT. int+NAN+DPAT were compared to int+DPAT $-{ }^{\mathrm{xxx}} \mathrm{p}<0.001,{ }^{\mathrm{xx}} \mathrm{p}<0.01$; int+AM+AEA were compared to int+AEA $-{ }^{\$ \$ \$} \mathrm{p}<0.001 . \mathrm{B} .{ }^{+++} \mathrm{p}<0.001,{ }^{++} \mathrm{p}<0.01 \mathrm{vs} .1 \mathrm{~h} \mathrm{HS}$; ${ }^{x x x} \mathrm{p}<0.001,{ }^{\mathrm{xx}} \mathrm{p}<0.01$ vs. 1h HS+AEA+DPAT. 1h HS+NAN+DPAT were compared to $1 \mathrm{~h}$ HS+DPAT $-{ }^{\$ \$ \$} \mathrm{p}<0.001,{ }^{\$ \$} \mathrm{p}<0.01 ; 1 \mathrm{~h}$ $\mathrm{HS}+\mathrm{AM}+\mathrm{AEA}$ were compared to $1 \mathrm{~h} \mathrm{HS}+\mathrm{AEA}-{ }^{k \& \&} \mathrm{p}<0.001$

(int+DPAT, Fig. 2A) increased pain perception during the first 30 min compared to controls. Instead, an increase in h-SIA was observed after $1 \mathrm{~h}$ HS on the $10^{\text {th }} \mathrm{min}$, with $1 \mathrm{~h}$ HS+DPAT-animals- PP-thresholds higher than control levels for the first $20 \mathrm{~min}$ of the experiment (Fig. 2B). AEA alone administration in intact animals (int+AEA, Fig. 2A) led to a transient increase in PP-thresholds for the first 20 min compared to controls. After $1 \mathrm{~h} \mathrm{HS}$, instead, AEA increased h-SIA for the whole time estimated (Fig. 2B).

NAN-pretreatment before DPAT-administration in intact animals (int+NAN+DPAT, Fig. 2A)revealed PP-thresholds higher than control levels for the entire time of the experiment. PP-thresholds estimated were also higher than int+AEA+DPAT for the first $30 \mathrm{~min}$ of the experiment. NAN-pretreatment after the end of $1 \mathrm{~h}$ HS and before DPAT-administration (1h HS+NAN+DPAT, Fig. 1B) decreased h-SIA for the entire time of the experiment. PP-thresholds of $1 \mathrm{~h}$ HS+NAN+DPAT-animals were also lower than 1h HS+AEA+DPAT-thresholds for the whole time estimated; they were comparable to the control values except for the $20^{\text {th }}$ and $30^{\text {th }} \mathrm{min}$, when a transient increase was detected (Fig. 1B).
$\mathrm{CB} 1$ - and $5 \mathrm{HT}_{1 \mathrm{~A}}$-receptor agonists administration in animals after $1 \mathrm{~h}$ HS had a modulator type effect on h-SIA. Contemporal administration of AEA and DPAT after the end of heat stress was characterized by different PP-thresholds than the ones after each one of the substances applied alone (Fig. 2B). Instead, in intact animals, DPAT had a more prominent impact on nociception than AEA (Fig. 2A).

The ECS participates in mediation of stress (Patel et al. 2005; Dlugos et al. 2012). Several parallelisms between glucocorticosteroids and eCB's actions have been noticed (Patel et al. 2005; Steiner and Wotjak 2008; Hill and McEwen 2010; Dlugos et al. 2012). High CB1-receptor expression in several regions (i.e. hippocampus, amygdala and prefrontal cortex) involved in hypothalamo-pituitary axis (HPA) regulation has been detected (Steiner and Wotjak 2008). Interrelations between eCBs and the HPA have been additionally described. Glucocorticoids and eCBs cross-talk consists in mutual influence: it turns out that under basal and stressful conditionse CBs control the HPA (Rademacher et al. 2008; Steiner and Wotjak 2008; Ganon-Elazar and Akirav 2009; Hill and McEwen 2010), while in the same 
time eCBs synthesis depends on glucocorticoids (Rademacher et al. 2008; Hill et al. 2011). Such interactions finally aim at HPA-activation constriction, i.e. control of the stress-triggered reaction (Patel et al. 2004, 2005; Ganon-Elazar and Akirav 2009). Given the potentially harmful effect of stress it is not surprising that nature provided us with a stress-counter-regulating system (Valentino and Van Bockstaele 2015) and substantial body of evidences supports eCBs' participation it such a system (Patel et al. 2005; Rademacher et al. 2008; Steiner and Wotjak 2008; Ganon-Elazar and Akirav 2009; Hill and McEwen 2010; Hill et al. 2011; Dlugos et al. 2012). Pain suppression is important for stress-coping and eCBs seem to exert a bidirectional modulation effect on the stress-reaction: constriction of HPA further activation but potentiation of antinociception. Literature data support the modulating, rather than mediating, role of eCBs on non-opioid stress-induced analgesia (Suplita et al. 2006).

The serotonergic system is also engaged during stress, and some authors retain $5 \mathrm{HT}_{1 \mathrm{~A}}$-receptor's role pivotal for regulation of the stress-response (Lanfumey et al. 2008). Activation of the HPA by different stressful conditions is followed by changes in brain 5-HT turnover in various brain areas in both rodents and humans (Pei et al. 1990; Clement et al. 1993; Inoue et al. 1994).

Our experiments revealed that cannabinoids and 5-HT exerted opposite and time-dependent effects on nociception in intact animals and after stress. DPAT and the combination DPAT+AEA increased nociception during the first $30 \mathrm{~min}$ in intact animals, while decreased nociception was observed during the same period in animals after stress. A marked change in pro-/ anti- nociceptive activity of DPAT and AEA was also detected on the $30^{\text {th }}$ min (Fig. 3).

The role of $5 \mathrm{HT}_{1 \mathrm{~A}}$-receptors is essential in the mechanism ofaction of various drugs (Mongeau et al. 1997; Vujovic et al. 2019). The mechanism of some analgesics also relays on interactions between the cannabinoid and the serotonergic systems (Mallet et al. 2008). Exploring the interactions between different receptors and mediatory systems may give clues for new formulas, with more powerful analgesic effect and/or reduced negative consequences of implication of each one of the compounds alone.

Cannabinoid and serotonergic systems will attract even more future scientific attention given new emerging data

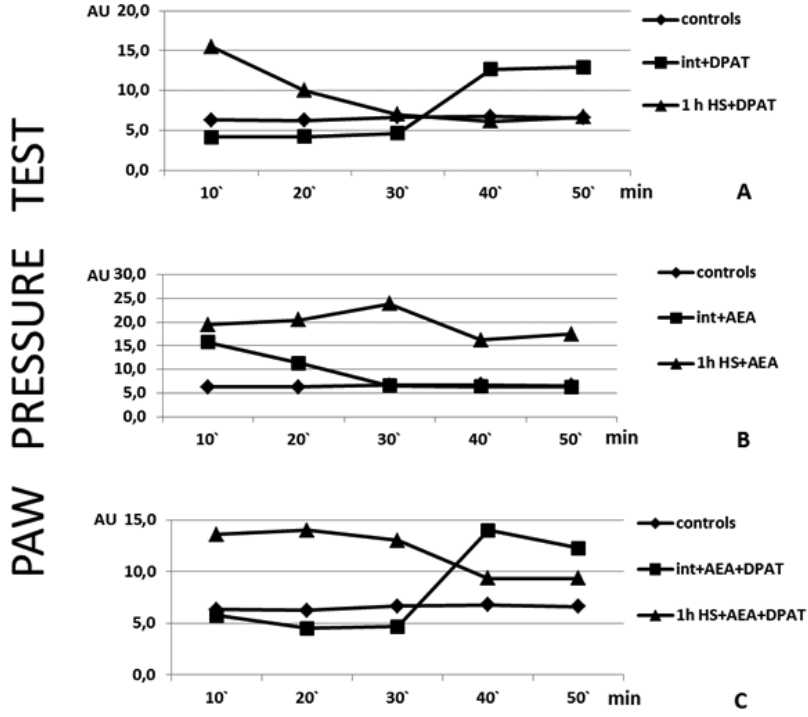

Figure 3. Bidirectional effects of (A) DPAT, (B) AEA, and (C) AEA+DPAT in intact animals and after $1 \mathrm{~h} \mathrm{HS}$.

about their participation in heteroreceptor complexes $\left(5-\mathrm{HT}_{1 \mathrm{~A}}-\mathrm{CB}_{2}\right.$, orexin1 receptor- $\left.\mathrm{CB}_{1}\right)$ implicated in morbidity and mortality (Franco et al. 2019), as well in the therapeutic approaches.

\section{Conclusions}

The endogenous cannabinoid and the serotonergic systems interact in nociception in intact animals as well as after heat stress. The ECS seems to have less prominent role in such interaction in intact animals than after heat stress. The interplay between the two systems seems to involve different mechanisms in intact animals and after heat stress with time-dependent effects. The interaction between the endogenous cannabinoid and the serotonergic systems exerts a modulating rather than mediating effect on h-SIA.

\section{Acknowledgements}

The present work was supported by a Grant D-61/03.05.2018 from the Medical Science Council of Medical University of Sofia.

\section{References}

Bambico FR, Hattan PR, Garant JP, Gobbi G (2012) Effect of delta-9-tetrahydrocannabinol on behavioral despair and onpre- and postsynaptic serotonergic transmission. Progress in Neuro-Psychopharmacology and Biological Psychiatry 38(1): 88-96. https://doi.org/10.1016/j. pnpbp.2012.02.006

Basbaum AI, Fields HL (1984) Endogenous pain control systems: brainstem spinal pathways and endorphin circuitry. Annual Reviewof Neuroscience 7: 309-338. https://doi.org/10.1146/annurev. ne.07.030184.001521
Boess FG, Martin IL (1994) Molecular biology of 5-HT receptors.Neuropharmacology 33(3-4): 275-317. https://doi.org/10.1016/00283908(94)90059-0

Casaril AM, Domingues M, de Andrade Lourenço D, Taborda Birmann P, Padilha N, Vieira B, Begnini K, Kommling FS, Collares T, Lenardão EJ, Savegnago L (2019) Depression- and anxiogenic-like behaviors induced by lipopolysaccharide in mice are reversed by a selenium-containing indolyl compound: Behavioral, neurochemical and computational insights involving the serotonergic system. 
Journal of Psychiatric Research 115: 1-12. https://doi.org/10.1016/j. jpsychires.2019.05.006

Clement HW, Schafer F, Ruwe C, Gemsa D, Wesemann W (1993) Stress-induced changes of extracellular 5-hydroxyindoleacetic acid concentrations followed in the nucleus raphe dorsalis and the frontal cortex of the rat. Brain Research 614(1-2): 117-124. https://doi org/10.1016/0006-8993(93)91024-M

Colpaert FC (2006) 5-HT1A receptor activation: new molecular andneuroadaptive mechanisms of pain relief. Current Opinion in Investigational Drugs 7(1): 40-47.

Darmani NA, Janoyan JJ, Kumar N, Crim JL (2003) Behaviorally active doses of the CB1 receptor antagonist SR 141716 Aincrease brain serotonin and dopamine levels and turnover. Pharmacology Biochemistry \& Behavior 75(4): 777-787. https://doi.org/10.1016/S00913057(03)00150-3

Dlugos A, Childs E, Stuhr KL, Hillard CJ, de Wit H(2012) Acute stress increasescirculating anandamide and other $\mathrm{N}$-acylethanolamines in healthy humans. Neuropsychopharmacology 37: 2416-2427. https:// doi.org/10.1038/npp.2012.100

Egashira N, Mishima K, Katsurabayashi S, Yoshitake T, Matsumoto Y, Ishida J, Yamaguchi M, Iwasaki K, Fujiwara M (2002) Involvement of5-hydroxytryptamine neuronal system in Delta(9)-tetrahydrocannabinolinducedimpairment of spatial memory. European Journal of Pharmacology 445(3): 221-229. https://doi.org/10.1016/S00142999(02)01755-7

Esteban S, García-Sevilla JA (2012) Effects induced by cannabinoids on monoaminergic systems. Progress in Neuro-Psychopharmacology \& Biological Psychiatry: 3878-3887.

Franco R, Villa M, Morales P, Reyes-Resina I, Gutiérrez-Rodríguez A, Jiménez J, Jagerovic N, Martínez-Orgado J, Navarro G (2019) Increased expression of cannabinoid CB2 and serotonin5-HT1A heteroreceptor complexes in a model of newborn hypoxic-ischemic brain damage. Neuropharmacology 152: 58-66. https://doi.org/10.1016/j. neuropharm.2019.02.004

Ganon-Elazar E, Akirav I (2009) Cannabinoid receptor activation in the basolateral amygdala blocks the effects of stress on the conditioning and extinction ofinhibitory avoidance. Journal of Neuroscience 29(36): 11078-11088. https://doi.org/10.1523/JNEUROSCI.1223-09.2009

Goldstein DS (2011) Stress, allostatic load, catecholamines, and other neurotransmitters in neurodegenerative diseases. Endocrine Regulations 45: 91-98. https://doi.org/10.4149/endo_2011_02_91

Haj-Dahmane S, Roh-Yu S (2011) Modulation of the serotonin system by endocannabinoid signaling. Neuropharmacology 61(3): 414-420. https://doi.org/10.1016/j.neuropharm.2011.02.016

Hill MN, McEwen BS (2010) Involvement of theendocannabinoid system in the neurobehavioral effects ofstress and glucocorticoids. Progress in Neuro-Psychopharmacology \& Biological Psychiatry 34(5): 791-797. https://doi.org/10.1016/j.pnpbp.2009.11.001

Hill MN, McLaughlin RJ, Pan B, Fitzgerald ML, Roberts CJ, Lee TT, Karatsoreos IN, Mackie K, Viau V, Pickel VM, McEwen BS, Liu QS, Gorzalka BB, Hillard CJ (2011) Recruitment of prefrontal cortical endocannabinoid signalingby glucocorticoids contributes to termination of the stress response. Journal ofNeuroscience 31(29): 10506-10515. https://doi.org/10.1523/JNEUROSCI.0496-11.2011

Howlett AC (2005) Cannabinoid receptor signaling. In: Pertwee R (Eds) Handbook of experimental pharmacology 168: 53-79. https://doi. org/10.1007/3-540-26573-2_2
Inoue T, Tsuchiya K, Koyama T (1994) Regional changes in dopamine and serotonin activation with various intensity of physical and psychological stress in the rat brain. Pharmacology Biochemistry \& Behavior 49(4): 911-920. https://doi.org/10.1016/0091-3057(94)90243-7

Kawashima T (2018) The role of the serotonergic system in motor control. Neuroscience Research 129: 32-39. https://doi.org/10.1016/j. neures.2017.07.005

Koleva K, Nikolov R (2018) Antidepressants-induced serotonin syndrome:literature review. Pharmacia 65(1): 64-70.

Lanfumey L, Mongeau R, Cohen-Salmon C, Hamon M (2008) Corticosteroid-serotonin interactions in the neurobiological mechanisms of stress-related disorders. Neuroscience and Biobehavioral Reviews 32(6): 1174-1184. https://doi.org/10.1016/j.neubiorev.2008.04.006

Lau T, Schloss P (2008) The cannabinoid CB1 receptor is expressed on serotonergicand dopaminergic neurons. European Journal of Pharmacology 578(2-3): 137-141. https://doi.org/10.1016/j.ejphar.2007.09.022

Lupien SJ, McEwen BS, Gunnar MR, Heim C (2009) Effects of stress throughout the lifespan on the brain, behaviour and cognition. Nature Reviews Neuroscience 10(6): 434-445. https://doi.org/10.1038/ nrn2639

Maletic V, Raison CL (2009) Neurobiology of depression, fibromyalgia and neuropathic pain. Frontiers in Bioscience 14(1): 5291-5338. https://doi.org/10.2741/3598

Mallet C, Daulhac L, Bonnefont J, Ledent C, Etienne M, Chapuy E, Libert F, Eschalier A (2008) Endocannabinoid and serotonergic systems are needed for acetaminophen-induced analgesia. Pain 139(1): 190200. https://doi.org/10.1016/j.pain.2008.03.030

Martikainen IK, Hirvonen J, Kajander J, Hagelberg N, Mansikka H, Någren K, Hietala J, Pertovaara A (2007) Correlation of human cold pressor pain responses with 5-HT(1A) receptor binding in the brain. Brain Research 1172: 21-31. https://doi.org/10.1016/j.brainres.2007.07.036

Mechoulam R, Parker LA (2013) The Endocannabinoid system and the brain. Annual Review of Psychology 641: 21-47. https://doi. org/10.1146/annurev-psych-113011-143739

Mico JA, Berrocoso E, Ortega-Alvaro A, Gibert-Rahola J, Rojas-Corrales MO (2006) The role of 5-HT1A receptors in research strategy for extensivepain treatment. Current Topics in Medicinal Chemistry 6(18): 1997-2003. https://doi.org/10.2174/156802606778522195

Millan MJ (2002) Descending control of pain. Progress in Neurobiology 66: 355-474. https://doi.org/10.1016/S0301-0082(02)00009-6

Mongeau R, Blier P, de Montigny C (1997) The serotonergic and noradrenergic systems of the hippocampus: their interactions and the effects of antidepressant treatments. Brain Research Review 23(3): 145-195. https://doi.org/10.1016/S0165-0173(96)00017-3

Nakazi M, Bauer U, Nickel T, Kathmann M, Schlicker E (2000) Inhibitionof serotonin release in the mouse brain via presynaptic cannabinoid CB1receptors. Naunyn- Schmiedeberg's Archives of Pharmacology 361(1): 19-24. https://doi.org/10.1007/s002109900147

Ohno-Shosaku T, Maejima T, Kano M (2001) Endogenous cannabinoids mediate retrograde signals from depolarized postsynaptic neurons to presynaptic terminals. Neuron 29(3): 729-738. https://doi. org/10.1016/S0896-6273(01)00247-1

Patel S, Roelke CT, Rademacher DJ, Cullinan WE, Hillard CJ (2004) Endocannabinoid signaling negatively modulates stress-induced activation of thehypothalamic-pituitary-adrenal axis. Endocrinology 145(12): 5431-5438. https://doi.org/10.1210/en.2004-0638 
Patel S, Roelke CT, Rademacher DJ, Hillard CJ (2005) Inhibition of restraintstress-induced neural and behavioural activation by endogenous cannabinoidsignalling. European Journal of Neuroscience 21(4): 1057-1069. https://doi.org/10.1111/j.1460-9568.2005.03916.x

Pei Q, Zetterstrom T, Fillenz M (1990) Tail pinch-induced changes in the turnover and release of dopamine and 5-hydroxytryptamine in different brain regions of the rat. Neuroscience 35(1): 133-138. https:// doi.org/10.1016/0306-4522(90)90127-P

Rademacher DJ, Meier SE, Shi L, Ho WS, Jarrahian A, Hillard CJ (2008) Effects of acute and repeated restraint stress on endocannabinoid content inthe amygdala, ventral striatum, and medial prefrontal cortex in mice. Neuropharmacology 54(1): 108-116. https://doi. org/10.1016/j.neuropharm.2007.06.012

Salzer I, Boehm S (2018) Serotonin: The Mediator that spans evolution. Regulation of nociceptor by serotonin. Pilowsky PM (Eds) Accademic press, 420 pp. https://doi.org/10.1016/B978-0-12-800050-2.00014-0

Schlicker E, Timm J, Zentner J, Göthert M (1997) Cannabinoid $\mathrm{CB} 1$ receptor-mediated inhibition of noradrenaline release in the human andguinea-pig hippocampus. Naunyn-Schmiedeberg's Archives of Pharmacology 356(5): 583-589. hhttps://doi.org/10.1007/ PL00005093

Seyrek M, Kahraman S, Deveci MS, Yesilyurt O, Dogrul A (2010) Systemic cannabinoids produce CB1-mediated antinociception by activation ofdescending serotonergic pathways that act upon spinal 5-HT7 and 5-HT2A receptors. European Journal of Pharmacology 649(1-3): 183-194. https://doi.org/10.1016/j.ejphar.2010.09.039

Steiner MA, Wotjak CT (2008) Role of the endocannabinoid system in regulationof the hypothalamic-pituitary-adrenocortical axis. Prog- ress in Brain Research 170: 397-432. https://doi.org/10.1016/S00796123(08)00433-0

Suplita II RL, Gutierrez T, Fegley D, Piomelli D, Hohmann AG (2006) Endocannabinoids at the spinal level regulate, but do not mediate,nonopioid stress-induced analgesia. Neuropharmacology 50(3): 372-379. https://doi.org/10.1016/j.neuropharm.2005.10.007

Valentino RJ, Van Bockstaele E (2015) Endogenous opioids: The downside of opposing stress. Neurobiol Stress 1: 23-32. https://doi. org/10.1016/j.ynstr.2014.09.006

van Dijk G, Buwalda B (2008) Neurobiology of the metabolic syndrome: an allostaticperspective. European Journal of Pharmacology 585(1): 137-146. https://doi.org/10.1016/j.ejphar.2007.11.079

Vujovic KS, Vuckovic S, Vasovic D, Medic B, Stojanovic R, Divac N, Srebro D, Prostran M (2019) Involvement of serotonergic and opioidergic systems in the antinociceptive effect of ketamine-magnesium sulphate combination in formalin test in rats. Pharmacological Reports 71(6): 1014-1019. https://doi.org/10.1016/j.pharep.2019.05.020

Wei H, Pertovaara A (2006) 5-HT1A receptors in endogenous regulation ofneuropathic hypersensitivity in the rat. European Journal of Pharmacology 535(1-3): 157-165. https://doi.org/10.1016/j.ejphar.2006.02.019

Woodhams SG, Chapman V, Finn DP, Hohmann AG, Neugebauer Volker (2017) The cannabinoid system and pain. Neuropharmacology 124: 105-120. https://doi.org/10.1016/j.neuropharm.2017.06.015

Yoshimura M, Furue H (2006) Mechanisms for the anti-nociceptive actions of the descending noradrenergic and serotonergic systems in the spinal cord. Journal of Pharmacological Sciences 101(2): 107117. https://doi.org/10.1254/jphs.CRJ06008X 